\title{
Five-Year Success and Failure Assessment of Four Implant Systems
}

\author{
${ }^{1}$ Mohammad HoseinKalantarMotamedi, ${ }^{2}$ MasoomehAmiri, ${ }^{3}$ Venus Hosseinzadeh, \\ ${ }^{4}$ Maryam Haghighattalab, ${ }^{5}$ MohadesehBalvardi \\ ${ }^{1}$ Professor of Oral and Maxillofacial Surgery, Trauma Research Center,Baqiyatallah University of \\ Medical Sciences and CMF Research Center Azad Islamic University of Medical Sciences. \\ ${ }^{2}$ Private practice dentistry, Tehran,Iran. \\ ${ }^{3}$ Private practicedentistry, Tehran, Iran. \\ ${ }^{4}$ Private practicedentistry, Tehran, Iran. \\ ${ }^{5}$ Biostatistics Department, Shiraz University of Medical Sciences,Shiraz,Iran.
}

\begin{abstract}
:
Aim: In this study a total of 192 implantsof four implant systems (Dentium, DentiumSuperline, Bego, SGS) placed immediately or delayed in 78 patients were assessed

Materials and Method: Patient's demographics and data on grafts,implant system, size, position, and method of insertion were collected. The follow-up evaluation of the 78 patients wasbetween 2months to 5 years postsurgery. Clinical parameters (bleeding,pocket depth, or implant mobility) were evaluated during follow up.Clinical comparisons were performed to evaluate implant loss in relation to implant brand, size, position, sex, age, systemic disease, graft,and placement method.

Results: There was no clinical difference with respect to patient's sex or when comparing the different placement methods. A higher failure rate was found for short implants in the anterior region of the maxilla and as age increases. Over a period of 5 years, the overall implant survival rate was $89.9 \%$ in the maxilla and $94.2 \%$ in the mandible
\end{abstract}

Conclusion: The average overall survival rate of the implants in general was over $90 \%$.

Keywords: Delayed implant placement, immediate implant placement, long-term investigation

\section{INTRODUCTION}

Dental implants can be placed immediately after tooth extraction or after extraction and healing of the tooth socket. Immediately placed implants offer several advantages for the patient as well as for the clinician, including shorter treatment time, less bone resorption (before placement), fewer surgical sessions, easier definition of the implant position (via the tooth socket), and perhaps better opportunities for osseointegration because of the healing potential of the fresh extraction site.1-3

A number of animal studies have reported that successful osseointegration is possible when implants areplaced immediately after tooth extraction, with or with- out the help of guided bone regeneration procedures.4-9

The success rate of a 3-year report of immediate and delayed implantation into the extraction socket were similar to those obtained for the placement of an implant into an ossified extraction site according to the standard protocol and were in agreement with other human studies of immediate implant placement, namely over \%90.10-16 Long-term data for immediate implants are available for up to 5 years. $17-18$

The purpose of this study was to evaluate the 5-year success rate of immediate and delayed placement with respect to implant size, system, position, placement methods, grafts, and patient demographics. 


\section{Materials ANd Methods}

A total of 78 patients ( 54 females and 24 males), were treated with implants at a single center by the primary author immediately (after extraction) or delayed (1 month or more postextraction).

The methods used for implantation were:

1. Implant placed immediately after tooth extraction (immediate placement). No membranes were used.

2. Implant was placed after of one month or more (delayed placement). No membranes were used.

3. Delayed placement plus membranes, TCP, bone grafts, or collagen was used in combination with the above.

One hundred ninety two implants were placed (89 in the maxilla and 103in the mandible) between February 2011 and February 2016.

Method 1 was used for 48 implants (30 in the maxilla, 18 in the mandible); Method 2 was used for 123 implants (49 in the maxilla, 74 in the mandible);

Method 3 was used was used in 21 implants; 11 in combination with method 1 (5 in the maxilla, 6 in the mandible) and 10 in combination with method 2 ( 5 in the maxilla, 5 in the mandible).

Patientsex,age, implant system, implant size, site and jaw, method of insertion.graftuse and presence of systemic disease were evaluated and thedata variables were analyzed as well as clinical parameters (bleeding, pocket depth, implant mobility, implant loss, pain etc) and complications and were evaluated.

The follow - up evaluation was done on 78 patients 2 months to 5 years after surgery. A successful treatment (according to Albrektssonetal18) was defined as a stable implant without any pathologic findings.Clinical stability, and periapicalradiography was used to assessed the implants.

Cox regression analysis was used to evaluate the influence of gender, age, implant system, implant location (maxilla or mandible),implant size ,placement methodand implant failure. When comparing failure rates between methods of insertion,different implant sites, different implant systems, use of grafts and patient gender, the chi-square was used.

\section{RESUltS}

Implant Loss. Of the 192implants placed(Table 1),15 failed (9 inmaxilla and 6 in mandible) (Table 2).

Table1. Number of Implants Placed According to Placement Method Immediate Placement Delayed Placement

\begin{tabular}{|l|l|l|l|l|}
\hline & M & M1,3 & M2 & M2,3 \\
\hline Maxilla & 30 & 5 & 49 & 5 \\
\hline Mandible & 18 & 6 & 74 & 5 \\
\hline Total & 48 & 11 & 123 & 10 \\
\hline
\end{tabular}

Placement methods: $1=$ immediate placement; $2=$ Delayed placement; $3=$ membranes ,Tricalcium phosphate (TCP), bone grafts, or TCP collagen used.

Table2. Implant Lossin Relation to Gender

\begin{tabular}{|c|c|c|c|}
\hline & Males & Females & Total \\
\hline Placed & 60 & 132 & 192 \\
\hline Lost & 4 & 11 & 15 \\
\hline
\end{tabular}

Table3. Implant Losses in Presence of Systemic Disease

\begin{tabular}{|l|l|l|l|}
\hline Implants & $\begin{array}{l}\text { Systemic disease } \\
\text { Yes }\end{array}$ & $\begin{array}{l}\text { Systemic disease } \\
\text { No }\end{array}$ & Total \\
\hline Placed & 58 & 134 & 192 \\
\hline Lost & $8(13 \%)$ & $7(5.2 \%)$ & 15 \\
\hline
\end{tabular}


Five-Year Success and Failure Assessment of Four Implant Systems

Table4. Implant Loss in Relation to Grafts Used

\begin{tabular}{|l|l|l|l|}
\hline & $\begin{array}{l}\text { Grafts } \\
\text { Yes }\end{array}$ & $\begin{array}{l}\text { Grafts } \\
\text { No }\end{array}$ & \\
\hline Placed & 21 & 171 & 192 Total \\
\hline Lost & 0 & $15(8.8 \%)$ & 15 Total \\
\hline
\end{tabular}

Implant Loss in Relation to Gender. No significant relationship was found between implant failure and gender(p>.05)(Table2)

Implant Loss in Relation to Grafts. None of the 21implants with grafts failed (Table4).

Table5. Implant Lossin Relation to Method of Insertion

\begin{tabular}{|l|l|l|l|}
\hline & Immediate & Delayed & Total \\
\hline Placed & 59 & 133 & 192 \\
\hline Lost & $5(8.5 \%)$ & $10(7.5 \%)$ & 15 \\
\hline
\end{tabular}

Table6. Implant Failures in Relation to Placement position in the Jaw

\begin{tabular}{|l|l|l|l|l|}
\hline & \multicolumn{2}{|c|}{ Maxilla } & \multicolumn{2}{c|}{ Mandible } \\
\hline & Anterior & Posterior & Anterior & Posterior \\
\hline Placed & 32 & 57 & 8 & 94 \\
\hline Lost & $4(12.5 \%)$ & $5(8.8 \%)$ & 0 & $6(6.4 \%)$ \\
\hline
\end{tabular}

Table7. Implant Failures Related to Implant System

\begin{tabular}{|l|l|l|l|l|}
\hline & Delayed & Immediate & Failed \\
\hline & Placed & Failed & Placed & 0 \\
\hline BEGO & 48 & $6(12.5)$ & 6 & $0(0 \%)$ \\
\hline SGS & 53 & $3(5.6 \%)$ & 23 & $4(31 \%)$ \\
\hline Implantium & 27 & $1(3.7)$ & 13 & $1(5.8 \%)$ \\
\hline Super Line & 5 & $0(0 \%)$ & 17 & 17 \\
\hline
\end{tabular}

Implant Loss in Relation to Placement Method. Of the 15 implants that failed, 5 had been immediately placed (method 1), 10 had been placed after one month or more healing period (method 2).The failure rate between immediate or delayed implant placement was not statically significant (p>.05)(Table5)

Implant Loss in Relation to Implant Position. The failure rate for implants placed in anterior maxilla was higher than that for implants in the posterior region (12.5\% versus $8.8 \%$ ) (Table 6) but this was not significant. In the mandible, the difference in failure rates was $6.4 \%$ for the posterior versus $0 \%$ for the anterior regions. The posterior region of mandible showed significantly higher success rate $(\mathrm{p}<.05)$

Implant Loss in Relation to Implant System. Of the 15 implants that failed, 6 were BEGO (Germany),5were Dentium (Korea),3 were SGS (Lithuania) and 1 was Superline (Korea)which was statically significant $(\mathrm{p}<.05)($ Table 7$)$

Implant Loss in Relation to Patient Age. Increasing age was associated with a higher risk of implant failure $(\mathrm{p}<.05)($ Table 8$)$

Implant Loss in Relation to Implant Size. Decreasing implant length and diameter was associated with high risk of implant failure $(\mathrm{p}<.05)($ Table 8$)$

Table8. Attributes of 192 Patients Applied in the Modeling Process

\begin{tabular}{|l|l|}
\hline Variable Name & Mean \pm SD \\
\hline Age & $52.65 \pm 11.22$ \\
\hline Diameter & $3.89 \pm 0.67$ \\
\hline Length & $10 \pm 1.07$ \\
\hline
\end{tabular}


Mohammad HoseinKalantarMotamedi et al.

Table9. Variables in the Equation

\begin{tabular}{|l|l|l|l|l|l|l|}
\hline & B & SE & Wald & Df & Sig & $\operatorname{Exp}(\mathrm{B})$ \\
\hline Sex & .366 & .196 & 3.494 & 1 & .062 & 1.442 \\
\hline Age & .016 & .008 & 4.118 & 1 & .042 & 1.016 \\
\hline SGS & & & 87.346 & 3 & .000 & \\
\hline BEGO & 1.048 & .826 & 51.832 & 1 & .000 & 2.851 \\
\hline IMPLANTIUM & 1.001 & .370 & 11.979 & 1 & .001 & 2.721 \\
\hline SUPERLINE & 1.216 & .359 & 11.457 & 1 & .001 & .296 \\
\hline Diameter & -.359 & .157 & 5.225 & 1 & .022 & .698 \\
\hline Length & -.184 & .089 & 4.280 & 1 & .039 & .832 \\
\hline Anterior maxilla & & & 6.939 & 3 & .074 & .803 \\
\hline Posterior maxilla & -.060 & .241 & .062 & 1 & .72 & .942 \\
\hline Anterior mandible & .163 & .192 & .723 & 1 & .395 & 1.177 \\
\hline Posterior mandible & -.959 & .417 & 5.305 & 1 & .021 & .383 \\
\hline Method of insertion & -.343 & .202 & 2.880 & 1 & .090 & .710 \\
\hline graft & -.599 & .267 & 5.037 & 1 & .025 & .549 \\
\hline
\end{tabular}

No relationship $(\mathrm{P}>$. 05) was found between implant failures and gender or for method of placement. But there was a significant relation between implant failure and implant length, diameter, site, use of graft and patient age. $(\mathrm{P}<.05)($ Table9)

Table10. The Frequency Table of Success and Failure During a 5 Year Period

\begin{tabular}{|l|l|l|}
\hline Status & Frequency & Percent \\
\hline Success & 177 & 92.2 \\
\hline Failure & 15 & 7.8 \\
\hline Total & 192 & 100 \\
\hline
\end{tabular}

Complications. As previously described, 15/192 implants were lost. Mobility was seen in 1 patient, thread exposure was reported in 2 patients. pain was also documented for 1 patient. There was no significant difference in complications between the different placement methods.

\section{Discussion}

Placing an implant into a fresh extraction socket seems to offer many advantages for the patient and for the clinician (e. g., shorter treatment time and fewer surgical sessions).1-3

The first 6 months post-extraction are critical because the highest rate of bone resorption occurs during this period.19-22Therefore, immediate or delayed insertion after extraction can be a realistic opportunity to reduce post-extraction bone loss. This method is an important modification of the older surgical protocol, recommending a 12- month healing period between tooth extraction and placement of implants, 23 and, in our opinion, is especially indicated in the esthetic regions of the jaws.

A cumulative survival rate of $89.9 \%$ for the maxilla and $94.2 \%$ for the mandible is similar to survival rates described in other studies that examined delayed or immediate implantation methods.10,18 The anatomic characteristics of the extraction socket after tooth extraction varies, after 1 year of healing. Implants placed immediately into fresh extraction sites engage prepared bony walls only at their apex, whereas the coronal space is filled by the end of the healing phase of osseointegration. This is why most of the studies focus on this interval to define survival rates .24

There are few human studies with more that 50 immediately placed screw-type titanium implants published 12,14,17,25-27 but they all show a high rate of survival, ranging between 93.9\% and $100 \%$.

However, sometimes it is very difficult to obtain good primary stability in a fresh extraction socket in the posterior maxilla with short and narrow implants, or implants with wider diameters could perhaps have better prognoses.

Comparing the results of the different methods used in this study, there was no difference, regardless of whether an implant was placed immediately after tooth extraction or after allowing several months of soft and hard tissue healing, if no membranes were used. These results correspond well with the results published by others such as Mensdorff-Pouillyet al.28

The presence of voids or gaps between implant and bone seems crucial.29,30,31 and this fact could be the reason for an increased risk of poor osseointegration. 
Regarding the importance of gap-filling materials, the impression obtained from the literature is that autologous bone grafts seem to be gold standard and the best filler material,25,32 but implants placed into fresh extraction sites without augmentation or grafting also had excellent long- term results.27 The need for bone augmentation and also for primary flap closure has yet to be proven.33 Although growth factors such as IGF-1, and rhop- I have been tested as bone formation promoters in fresh extraction sites, the results are still questionable.34,35

Histological studies in dogs did not show better bone- implant contact ratios with membranes.36 On the contrary, several studies have shown that membrane exposure led to complications, 12,14,17 such as bone resorption or failure of the implant.37

Therefore, within the limits of this study, we can conclude that the simplest method of placing implants into fresh extraction sites, may be recommended as we have obtained a high survival rate and implant with bioactive coating (i.e. SGS) can increase implant survival rates.

\section{Conclusion}

This study demonstrated that implants placed according to an immediate or delayed method can be successful for at least 5 years. The success rate of $89.9 \%$ for the maxilla and $94.2 \%$ for the mandible is comparable with the outcomes of other studies. The risk factor of failures in this study are similar to those described in other studies, i.e, short implants, soft bone ,systemic diseases, maxillary and anterior sites etc.)

\section{REFERENCES}

[1] Lazzarra RJ. Immediate implant placement into extraction sites: Surgical and restorative advantages. Int J PeriodonticsRestorative Dent 1989 ;9:333-343 .

[2] Parel SK, Triplett RG.Immediate fixture placement.A treatment planning alternative.Int J Oral Maxillofac Implants 1990 ;5:337-345 .

[3] Werbitt MJ, Goldberg PV. The immediate implant. Bone preservation and bone regeneration. Int J PeriodonticsRestorative Dent $1992 ; 12: 207-217$.

[4] Caudill RF, Meffert RM. Histologic analysis of the osseoin- tegration of endosseous implants in simulated extraction sockets with and without e-PTFE barriers. Part I: Prelimi- nary findings. Int J PeriodonticsRestorative Dent1991;11:207-215 .

[5] Warren K, Gotfredsen K, Hjørting-Hansen E, Karring T. Guided tissue regeneration ensures osseointegration of dental implants placed into extraction sockets. An experi- mental study in monkeys.Clin Oral Implants Res1991;2:166-171 .

[6] Lundgren D, Rylander H, Andersson M, Johansson C, Albrektsson T. Healing-in of root analogue titanium implants placed in extraction sockets. Clin Oral Implants Res $1992 ; 3: 136$ 143 .

[7] Ettinger RL, Spivey JD, Han D, Koorbusch GF. Measure- ment of the interface between bone and immediate endosseous implants. A pilot study in dogs.Int J Oral Maxillofac Implants 1993 ;8:420-427 .

[8] Barzilay I, Graser GN, Iranpour B, ProskinHM . Immediate implantation of pure titanium implants into extraction sockets of Macacafascicularis. Part I: Clinical and radiographic assessment. Int J Oral Maxillofac Implants1996 ;11:299-310 .

[9] Barzilay I, Graser GN, Iranpour B, Natiella JR, ProskinHM . Immediate implantat ion of pure titanium implants into extraction sockets of Macacafascicularis. Part II: Histologic observations. Int J Oral Maxillofac Implants 1996 ;11:489-497 .

[10] Grunder U, Polizzi G, Goene R, et al .A 3year prospective multicenter follow- up report on the immediate and delayed-immediate placement of implants . Int J Oral maxillofac Implants 1999; 14:210-216.

[11] Tolman DE, Keller EE.Endosseous implants placed imme- diately following dental extraction and alveoloplasty. Pre- liminary report with 6-year follow up.Int J Oral Maxillo- fac Implants $1991 ; 6: 24-28$.

[12] Becker W, Dahlin C, Becker B, Lekholm U, van Steen- berghe D, Higuchi K, Kultje C. The use of e-PTFE barrier membranes for bone promot ion around titanium implants placed into extraction sockets: A retrospective multicenter study. Int J Oral MaxillofacImplants $1994 ; 9: 31-$ 40. 
[13] Mensdorff-Pouilly N, Haas R, Mailath G, Watzek G. The immediate implant. A retrospective study comparing the different types of immediate implantat ion. Int J Oral Max- illofac Implants $1994 ; 9: 571-578$.

[14] Augthun M, Yildirim M, Spiekerman H, Biesterfeld S. Healing of bone defects in combination with immediate implants using the membran e technique. Int J Oral Max- illofac Implants 1995 ;10:412-428 .

[15] Watzek G, Haider R, Mensdorff-Pouilly N, Haas R. Imme- diate and delayed implantat ion for complete restorat ion of the jaw following extraction of all residual teeth. A retro- spective study comparing different types of serial immedi- ate implantat ion. Int $\mathbf{J}$ Oral Maxillofac Implants1995;10:561-567 .

[16] Rosenquist B, Grenthe B. Immediate placement of implants into extraction sockets: Implant survival. Int J Oral Max- illofac Implants $1996 ; 11: 205-209$.

[17] Gelb DA. Immediate implant surgery: Three-year retro- spective evaluation of 50 consecutive cases. Int J Oral Maxillofac Implants 1993 ;8:388-399 .

[18] Polizzi G Grunder U, Goene R, et al.immediate and delayed implant placement into extaractionsocket:A 5-year report.Clinical Implant Dentistry and Related Research 2000;2:93-99.

[19] Wictorin L. Bone resorption in cases with complete upper denture.ActaRadiol (Diagn) 1964; (Suppl 228): 1-97.

[20] Tallgren A. The continuing reduction of the residual alveolar ridges in complete denture wearers: a mixed longitudinal study covering 25 years. J Prosthet Dent 1972; 27:120-132.

[21] Carlsson GE, Persson G. Morphologic changes of the mandible after extraction and wearing dentures. Odontol Rev 1967; 18: 27-54.

[22] Carlsson GE, Haraldson T. fundamental aspects of mandibular atrophy. In: Worthington P, Branemark P-I, eds. Advanced osseointegration surgery: applications in the maxillofacial region. Chicago: Quintessence, 1992: 109-18.

[23] Adell R, Lekholm U, Rockler B, Branemark P-I. A 15-year study of osseointegrated implant in the treatment of the edentulous jaw. Int J Oral surg 1981; 10387-416.

[24] Schartz - Arad D, Chaushu G. The ways and wherefores of immediate placement of implants into fresh extraction sites: a literature review. J Periodontol 1997; 68: 915-923.

[25] Becker W, Becker BE, Polizzi G. Bergstrom C. Autogenous bone grafting of bone defects adjacent to implants placed into immediate extraction sockets in patients: a prospective study. Int Oral Maxillofac Implants 1994; 9: 389-396.

[26] Bragger U, Hammerle CHF, Lang NP. Immediate transmucosal implants using the principle of guided tissue regeneration. (II) A cross-sectional study comparing the clinical outcome 1 year after immediate to standard implant placement. Clin Oral Impl Res 1996; 7:268-276.

[27] Becker BE, Becker W, Ricci A, Geurs N.A Prospective clinical trial of endosseous screwshaped implants placed at the time of tooth extraction without augmentation. J Periodontol 1998; 69: 920- 926.

[28] Altman DG: Practical statistics for medical research. London: Chapman \& Hall, 1991.

[29] Carlsson L, Rostlund T, Albrektsson B, Albrektsson T. Implant fixation improved by close fit. Cylindrical implant bone interface studied in rabbits. ActaOrthopScand 1988; 59: 272-275.

[30] Wilson TG Jr. Shenk R, Buser D, Cochran D. Implants placed in immediate extraction sites: a report of histologic and histometric analyses of human biopsies. Int J Oral Maxillofac Implants 1998; 3: 333-341.

[31] Akimoto k, Becker W, Persson R, et al. Evaluation of titanium implants placed into simulated extraction sockets: a study in dogs. Proceedings of Osseointegration 14th Annual Meeting, in the osseous reconstruction of alveolar and palatal clefts. Oral MaxillofacSurgClin North Am 1991; 3: $589-597$

[32] Boyne P. Bone grafting in the osseous reconstruction of alveolar and palatal clefts. Oral MaxillofacsurgclinNorth Am 1991; 3:589-579.

[33] Schwartz- Arad D, Chaushu G. Immediate implant placement: a procedure without incisions. J Periodontol 1998; 69: 743-750. 
[34] Becker W, Lynch SE, Lekholm U, et al. A comparison of Eptfe membranes alone or in combination with plateletderived growth factors and insulin- like growth factor.1 or demineralized freeze-dried bone in promoting bone formation around immediate extraction socket implants. J Periodontol 1992; 63: 929-940.

[35] Cook SD, Salkeld SL, Rueger DC. Evaluation of recombinant human osteogenic protein-1 (rhOp-1) placed with dental implants in fresh extraction socket implants. J Periodontol 1992; 63: 929-940.

[36] Gotfredsen K, Nimb L, Buser D, Hjorting- Hansen E.Evaluation of guided bone regeneration around implants placed into fresh extraction sockets: an experimental study in dogs. J Oral MaxillofacSurg 1993; 51: 879-884.

[37] Celletti R, Davarpanah M, Etienne D, et al. Guided tissue regeneration around dental implants in immediate extraction sockets: comparison of e- PTFE and a new titanium membrane. Int $\mathbf{J}$ PeriodontRestor Dent 1994; 14:243-253. 